\title{
The Importance of Organic Agriculture and Şanlıurfa Farmers' Perspectives on Organic Products
}

\author{
Ayşe Çalık ${ }^{1, a, *}$ \\ ${ }^{I}$ Department of Field Crops, Faculty of Agriculture, Harran University, 63300 Şanluurfa, Turkey
}

*Corresponding author

\begin{tabular}{l|l}
\hline A R T I C LE I N F O & A B S T R A C T \\
\hline & Sustainable agriculture can be defined as the creation of an agricultural structure using agricultural
\end{tabular}

Research Article technologies that do not harm the environment in addition to the protection of Natural Resources in the long term. In Turkey, as in the developed countries of the world, intensive (traditional or intensive) agricultural production is used without considering the negative consequences of

Received : 10/12/2019

Accepted : 06/01/2020 processing techniques and technologies while using synthetic production inputs without supervision. Today, these applications have started to attract as much attention as waste industry or urban pollution with their effects on the determination of natural balance and the ability to create life hazard that can reach all living beings as well as human beings through the food chain. Therefore, organic farming techniques that meet quality, health and environmental standards play a key role by avoiding

Keywords:

Organic agriculture

Şanliurfa

Organic

Product

Village

the use of unnatural inputs such as pharmaceuticals, synthetic fertilizers. Organic agriculture, which is important for the reflection of sustainable agriculture in practice, has started to be seen as a necessity, especially with the development of environmental awareness in recent years. In this study, it is aimed to explain the basic principles of organic agriculture, which we believe are necessary for sustainable agriculture in the 8 villages, namely Umut, Günbalı, Yenisu, Mehmetçik, Güçlü, Akpınar, Güzel, Anaz and 3 towns (Kısas, Konuklu and Çamlıdere) in Şanlıurfa. According to the results of the survey, almost $30 \%$ of farmers were found to grow organic products. At the time of purchase, they answered the question of which products do you pay attention to organic, and more than half $(54.8 \%)$ of the surveyed farmers responded that they pay attention to food. $45.18 \%$ of the surveyed farmers stated that they did not pay attention to anything in shopping.

\section{Introduction}

Rapid industrialization and population growth experienced in the 20th. century brought about many important environmental problems. As a solution, policies for the elimination of the hunger problem have been developed and targets for high productivity from the unit area and opening up new areas to agriculture have not been determined by using intensive input. While the agricultural policies of the green revolution in the 1970s were only partially the solution to the problems of hunger, they were not able to help solve the problem completely. Ultimately, intense and unconscious use of pesticides and fertilizers, wrong tillage practices, residue and risk of the degradation of the physical structure of the soil, organic matter and nutrient balance of viability loss and degradation has brought important environmental problems such as salinization. As a result of these developments, an alternative system of production, organic agriculture or ecological agriculture, or biological agriculture with its name in Latin countries, has resulted in the emergence. This production system was first implemented by some European manufacturers who were highly sensitive to environmental problems. While the products produced in the first period were mostly consumed on farms or in the local markets in the immediate vicinity, the event gained a commercial dimension in the following years and gained increasing acceptance throughout the world after the 1980s. After the 1990s in European countries, Organic Agriculture developed rapidly in countries such as Austria, Germany, Luxembourg and Switzerland. Development of organic agricultural land from1985 to 2013 are shown in Figure 1. 


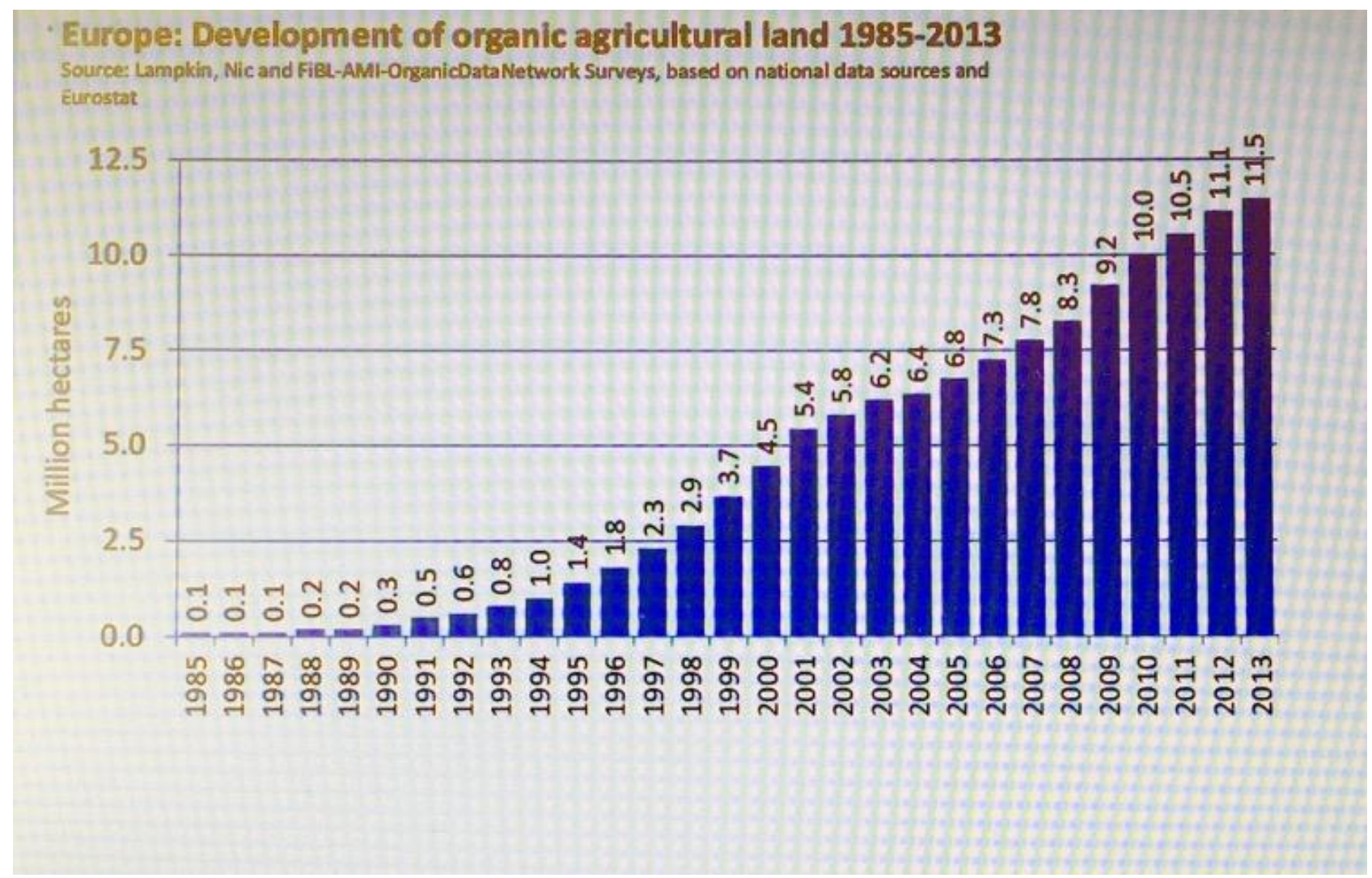

Figure 1. Development of organic agricultural land 1985-2013 (Willer and Lernoud, 2015)

\section{History of Organic Agriculture}

Human beings have gradually increased their dominance in the environment in which they live, but gradually over time. Agriculture, formerly known as the profession of slaves, has increasingly taken its important place in the present day. Rapid advances in industry and technology have highlighted the use of synthetic chemical fertilizers to get more products out of the unit area and synthetic chemical drugs to further perfect plant protection. The problems that began to appear in their one-sided use were noticed by scientists trained in agriculture. And they have tried to put forth their alternatives under the name of organic (ecological, biological) agriculture in order to sustain agriculture.

\section{Organic Agriculture in Turkey}

Organic agriculture in our country, 1984-1985 's traditional export of raisins and figs from abroad as an ecological demand began. In later years, the variety of products was shaped according to the demands from abroad. Almost all of the ecological products produced in our country are exported. The domestic market is to make up a very small share for now. In order to realize the healthy and balanced production of organic agriculture in Turkey, to bring together the relevant units and to support education and research, ETO (Ecological Agriculture Organization) Association was established in 1992. The association is involved in all activities related to organic agriculture and provides support. In terms of production areas, 1037 ha in 1990, the production area increased by about 43 times in 1999 to $4,455.5$ ha, the number of producers in 1990, 1037 in 9 years, the number of producers increased by 12 times in 1999 to 12,435 was seen (ETO, 2001).
In recent years, almost 200 organic products are grown in Turkey. Some of the ecological products produced in our country include: pistachios, almonds, walnuts, hazelnuts, raisins, prunes, apricots, cherries, chestnuts, figs, pears, apples, quince, lemon, mandarin, peach, Cherries, olives, peppers, peas, parsley, zucchini, broccoli, cauliflower, watermelon, melon, potato, eggplant, leeks, cucumbers, carrots, onions, barley, sunflower seed, anise seed, wheat, lentils, corn, cotton, sesame, peanut, vetch, oats, raspberries, strawberries, blackberries, rosehip, peppermint, nettle, rose water, rose oil, honey, wheat, black seed, molasses, tea, sumac, olive oil, pasta vs.

Ecological products produced in Turkey; 60\% of them are exported to Germany, $15 \%$ to EU countries, and most of the remaining to countries such as Switzerland, the United Kingdom, The Netherlands, France and Denmark (Itim, 2005).

The year 2000 in Turkey ecological production of the product crops are examined;

$65 \%$ of dry products, $18 \%$ field crops, $10 \%$ age fruits, $3 \%$ grape fruits, $2 \%$ vegetables, $1 \%$ medicinal plants, other plants account for $3 \%$ (A $\breve{g l}, 2006)$.

\section{Implementation of Organic Agriculture in Turkey}

A producer who decides to do organic farming should apply to one of the inspection and certification bodies one year before the start of production and ensure that the production is in compliance with the rules of "regulation on the principles and application of Organic Agriculture" and be certified. The certification body prepares the necessary documents on behalf of the manufacturer and reports them to the ministry and carries out the inspection of the land at least twice a year with or without notice. If the production has been made in accordance with the rules 
specified in the regulation, the certificate is issued. In order to start ecological production on a previously traditional agricultural land and obtain the ecological product certificate for the products obtained from it, it is necessary to complete the transition period of 2-5 years annually. During this process, production must be carried out in accordance with ecological production methods as stated in the regulation.

\section{Organic Farming}

It is a controlled and certified form of agricultural production in every stage from production to consumption, made with the use of inputs permitted under the regulation of organic agriculture without using synthetic chemical inputs and drugs in production. It also includes human and environment friendly production systems that aim to restore the natural balance lost as a result of faulty practices in the ecological system and is a form of production that demands the creation of all these possibilities in a closed system, besides the prohibition of the use of synthetic chemical drugs and fertilizers, organic and green fertilization, alternation, soil preservation, increase plant resistance.

\section{Purpose and Principles of Organic Agriculture}

To protect the environment, plant, animal and human health to the maximum degree without polluting soil and water resources and air. In organic agriculture there are different production methods for different plant and animal products and their common principles are as follows;

- First, all factors and events associated with production in agricultural production should be considered as a whole and the self-sufficiency of the agricultural enterprise engaged in ecological production should be ensured.

- All the effects of all raw materials and other business inputs that arise with agricultural production and which are supplied from the immediate environment should be reduced or tried to avoid them altogether.

- The improvement of the soil and the protection of the organisms in it, nutrition should be provided; the soil should not be exploited; on the contrary, natural productivity should be increased. If necessary to provide this alternation, organic fertilization should be done also appropriate tillage methods should be used.

- The resistance of plants against diseases and pests should be increased with some additional supports.

- In the selection of plant species and varieties, the ecological conditions of the region to be produced and the possibility of contracting diseases in these conditions should be taken into consideration. In addition, healthy, durable seeds, seedlings and animals should be used.

- In organic agriculture, besides the measures mentioned above in terms of Plant Health and the effects of which can be seen in a long time, the use of early warning systems and the promotion of beneficial living things is an important part of the concept of plant protection.

- Soil structure, improving and increasing the amount of humus measures together with soil-protective, energysaving, working conditions appropriate tillage methods should be applied.
- As is known, there is an inverse ratio between yield and quality in agricultural production. In general, balance must be established between the two. However, while this balance is created in organic agriculture, the increase in crop quality along with the increase in yield is negligible.

Fossil fuels and other energy sources, especially petroleum, should be used in accordance with the maximum saving rule to ensure optimum efficiency in an agricultural enterprise.

\section{Why Organic Farming?}

It significantly reduces the damage to human health by chemical production.

- By reducing soil erosion in large areas, it protects soil and fertilizer, which is the most important source of Agriculture.

- Increases productivity by protecting water resources and soil with appropriate tillage methods.

- Eco-friendly organic agriculture protects natural life as well as pastures where animal grazing is needed.

- The nutritional values of food and products produced by organic agriculture are maintained because no harmful pesticides or artificial sprayers or growers are added.

- Animals grazing in areas where organic farming is practiced are more resistant to infections and give more milk.

- Organic farming helps to preserve existing diversity and the disappearing natural seeds.

\section{Organic Farming in South-eastern Anatolia Region}

The South-eastern Anatolia is one of the first regions in the world where agriculture is done, consists of a collection of basins where many products can be produced according to the seasons of the year in terms of fertile soils, abundant water resources and suitable climatic conditions.

The total crop production area of the region is $3,212,086$ ha, of which $78.8 \%$ is field agriculture, $13.2 \%$ is orchard, $5.9 \%$ is fallow and $2.1 \%$ is vegetable area. Field agriculture in the region has the highest share of total area. The region has rates equivalent to $4 \%$ of the organic agricultural production in Turkey, $3 \%$ of the organic agricultural area and $3 \%$ of the number of organic farmers. However, with the presence of new irrigation areas and virgin areas, organic agricultural production values will increase every day (GTHB, 2015).

As of 2015,70366 tons of organic products are produced in 17,450 ha by 881 farmers in South-eastern Anatolia region (GTHB, 2015). In order to promote organic agriculture and to improve organic production, demonstration areas are established in all GAP provinces and training and dissemination activities are carried out for producers. The fact that there are large agricultural holdings in the region and the land is not fragmented is an important advantage in terms of organic production. This eliminates the risk of chemical-synthetic pesticide contamination from the neighbour in organic agriculture. Organic producers in the region will ensure the protection of soil fertility and the natural resources of the region by producing in a sustainable manner and contribute to the 
sustainability of the region. Thus, farmers engaged in organic farming will guarantee their livelihoods both now and in the future.

The GAP organic agriculture consultancy and distribution centre (GAP OTADAM) established within the scope of the project is one of the most important elements that distinguishes the region from other regions of Turkey in terms of organic production. This organic agriculture in all the provinces of the region with consultancy and Extension Centre members in the value chain of organic production, processing and marketing in the areas of information, guidance and provide consultancy services in the region and is intended to contribute to the dissemination of organic farming practices.

\section{Material and Method}

The main material of this study was the questionnaires conducted with a total of 220 farmers living in 8 villages, namely Umut, Günbalı, Yenisu, Mehmetçik, Güçlü, Akpınar, Güzel, Anaz and 3 towns (Kısas, Konuklu and Çamlıdere) in Şanlıurfa. The surveys were conducted in 2016-2017. In addition, national and international research findings related to the subjects were used to form the questions posed to our farmers.

As of 2016-2017, a total of 220 farmers living in 8 villages were surveyed in Şanliurfa. In the sample, the researchers attempted to select how many farmers with their knowledge and experiences. The data were arranged in accordance with the purpose of the study and obtained by using a questionnaire with the questions are presented in the results and discussion section of this study.

\section{Results and Discussion}

\section{State of Organic Agriculture in Şanlıurfa}

Şanlıurfa province will have a strong place in organic agricultural production in the future with its soil structure and water resources. On the other hand, there is a relatively small amount of chemicals used in the arid regions and these regions have a great potential in terms of organic agriculture. In addition, as a result of excessive irrigation, increased use of pesticides, insecticides and fertilizers in irrigated areas, ground waters began to become polluted, especially in Harran plain and part of Akçakale District, salinity and barren areas were formed. It is thought that by doing organic farming in these areas, the negative effects of traditional agriculture on the environment, albeit locally, can be reduced.

Şanliurfa is the province where red lentil is produced the most (120000 ha) in Turkey and average yield of it almost $90 \mathrm{~kg}$ per decares. Red lentil is grown in almost all of the districts except the irrigated areas of Akçakale and Harran districts, but it can take part crop rotation with wheat. Generally, in the dry farming areas, based on rainfall, very little fertilizer and chemicals are used. Rice is an important crop that can be grown organically in Şanlıurfa and leaves nitrogen residue on the soil after it. Approximately 30.000 da rice is grown and 14.000 tons of rice are produced in the region. Generally very little amount of chemicals are used in the rice production areas in Karacadağ region. Rice produced in Karacadağ is appealing to the people of the region with its unique flavour and preferred in this respect, has a high chance of being organically cultivated.

There are more than 10 million pistachio trees in Şanliurfa province and production is almost about 65000 tons. It is generally cultivated under dry conditions in Birecik and Bozova districts. The yield of pistachio, which is suitable for organically growing, can be increased under irrigated conditions. This traditional product is valued and is in the first place among organic products because of the ease of finding the market.

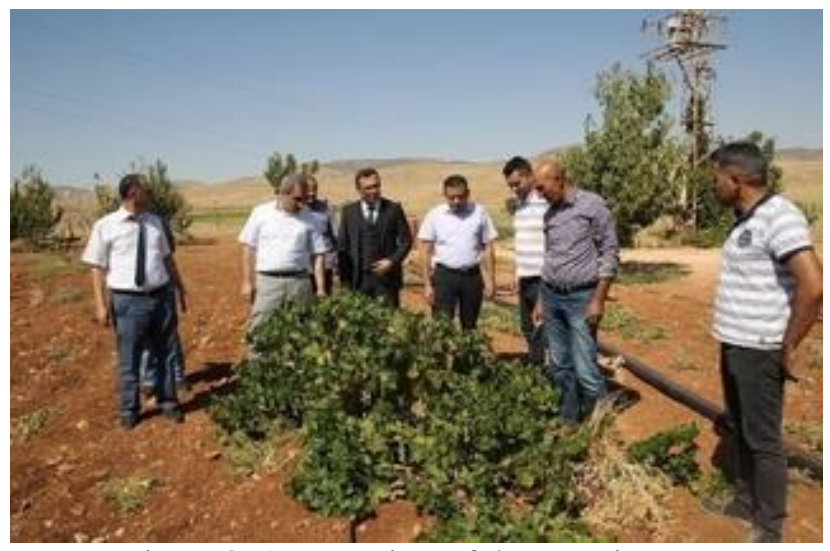

Figure 2. An overview of the experiment area

\section{Factors Affecting Consumers' Habit of Buying Organic Products}

Many factors affect the availability of organic products. In buying organic produce by farmers, pharmaceutical residues in non-organic food are more important to fencers than environmental concern. In addition, children's health is another important factor. Buying organic produce is a part of life for some consumer farmers and it is also considered an ideology and value system for some farmers. Organic product sign, natural production, health and environmental quality understanding, attractive product quality and price are other factors that are effective in purchasing. The willingness of farmers to pay more for organic food than traditional foods is considered a success of the organic product market. The organic product consumer profile can then be categorized as follows (Bourn and Prescot, 2002).

- Farmers who are environmentally conscious.

- Those concerned for chemical residues in foods.

- Humanist conscious farmers about modern agriculture.

- Those who believe that modern production products are better and tastier.

\section{Positive Factors}

In general, the most important reason why consumers, farmers, consume and buy organic foods, is that these foods are delicious and fresh. The other remaining factors are the belief that the nutritional values of organic products are higher than those grown in other traditional methods, and that organic products do not contain hormone and chemical drug residues. However, another reason why organic products are preferred is that organic products are environmentally friendly due to the lack of various chemicals. 


\section{Negative Factors}

Organic produce production requires serious experience and is difficult. Nonetheless;

- It is thought that it will not see sufficient value in the domestic market.

- No suitable market opportunities were provided.

- The market value of the product is very low as of market.

- The number of farmers who are experienced and able to understand organic agriculture in the domestic market is very low, many farmers who want to choose organic agriculture in this issue is undecided.

- Because agricultural land is scattered in our country, farmers are affected by harmful drugs and chemical products used by many agricultural lands in the environment, no matter how much they are interested in organic agriculture.

- The external appearance of organic products is not uniform and attractive.

With this study, it is aimed to explain organic agriculture to our consumer farmers in all aspects and to draw attention to organic agriculture, to raise awareness of organic agriculture and also to explain the functioning of organic agriculture production mechanisms.

For this, surveys were conducted in 8 villages and 3 towns where these villages are affiliated. According to the results of the survey, $62 \%$ of the 220 farmers interviewed in 440 households were male and $38 \%$ were female. The average age of 220 farmers is 35 .

As our surveys were filled out by the farmers of the region, naturally, $80 \%$ of the education level was determined to be above primary school graduates. Almost $30 \%$ of farmers were found to grow organic products. At the time of purchase, they answered the question of which products do you pay attention to organic, and more than half $(54.8 \%)$ of the surveyed farmers responded that we pay attention to food. $45.18 \%$ of the surveyed farmers stated that they did not pay attention to anything in shopping.

$30 \%$ of the respondents (72 people) applied organic agriculture, including milk and dairy products, poultry, eggs, etc. $20 \%$ of the respondents ( 88 households) cannot do organic farming due to insufficient financial situation.

In addition to the various demonstration works for these producers and farmers, the provincial and district directorates of Agriculture provide seed assistance to farmers who are in poor financial condition, as well as the distribution of poultry or sheep per household.

Our farmers who want to grow organic crops and cannot grow they will benefit from the studies that will be implemented in the said way. However, despite all this deficiency, $25 \%$ of our surveyed producers, i.e. 55 people, are conscious about organic production and do not prefer to use organic products, even though their financial situation is in place. The reasons for our farmers to act like this is because they are used to ready-made foods and market foods.

\section{Conclusion}

As a result, all farmers and producers in the region, for the development of organic farming, related organizations operating in agriculture, namely provincial/district directorates, universities, research institutes, training activities should be done, demonstrations in a relative way to grow the product and the production of organic agriculture should be spread. For this purpose, transferring the importance of factors affecting production to producers in a practical way especially with demonstrations will help to contribute to Şanliurfa province, region and even the national economy.

\section{References}

Anonymous. 2001. "Ecological Agriculture" Ecological Agriculture Organization Association, ETO. www.eto.org.tr. (Date of access July 2016).

Anonymous. 2005. Organic agriculture, İzmir Provincial Directorate of Agriculture, ITIM. www.tarim.gov.tr. (Date of access June 2016).

Anonymous. 2015. Plant Production, Organic farming, Statistics, GTHB. www.tarim.gov.tr. (Date of access June 2019).

Ağ Y. 2006. Turkey III. Organic agriculture final declaration of the symposium. Turkey III. Organic Agriculture Symposium. November 1-3, Atatürk Garden Cultures Central Research Institute, Yalova.

Bourn D, Prescott J. 2002. A comparison of the nutritional value, sensory qualities and food safety of organically and conventionally produced foods. Critical Reviews in Food Science and Nutrition, 42, 1-34.

Willer H, Lernoud, J. 2015. The world of organic agriculture. Statistics and Enginering Trends 2015. FiBL, Frick, and IFOAM-Organics International, Bonn. 